Article

\title{
The Impact of Life Trajectories on Retirement: Socioeconomic Differences in Social Support Networks
}

\author{
Francisca Ortiz ${ }^{1,2, *}$ and Elisa Bellotti ${ }^{1}$ \\ ${ }^{1}$ The Mitchell Centre for Social Network Analysis, University of Manchester, UK; \\ E-Mails: francisca.ortiz@manchester.ac.uk (F.O.), elisa.belloti@manchester.ac.uk (E.B.) \\ ${ }^{2}$ Millennium Institute for Caregiving Research (MICARE), Chile \\ * Corresponding author
}

Submitted: 4 May 2021 | Accepted: 29 July 2021 | Published: 15 December 2021

\begin{abstract}
In general, the literature about social support networks (SSNs) has been divided into two different statements: On the one hand, social support is a safety net that helps the ego confront disadvantages in life. On the other hand, studies have shown how SSNs could act as sources of constraints for ego, especially in poverty. In this study, we looked into the SSNs of older people over time and found how those two paths co-exist and depend on the socioeconomic status of ego. Then, this article aims to discover how cumulative social inequalities intersect with social networks in facilitating or hampering social support over time, impacting retirement experience. Specifically, we want to observe if and how the life trajectories of older people from different socioeconomic statuses affect how people build their SSNs in terms of structure and composition. This article presents a mixed-method project that collected qualitative life history interviews from 30 older women and men in Santiago, Chile. The results show that socioeconomic status plays a role in shaping individual experiences of retirement but that these experiences are shaped through SSNs structural and compositional characteristics. People identify salient life events and the relevant networks and conjointly discuss supportive and/or exploitative aspects of their networks. The amount of support they give to others or that they receive from their alters accumulates over time, resulting in a progressive social inclusion or exclusion mechanism. This article concludes that SSNs during retirement are shaped by the ego's socioeconomic status and life history.
\end{abstract}

\section{Keywords}

ageing population; life history; life trajectory; retirement; social support network; socioeconomic status

\section{Issue}

This article is part of the issue "In Good Company? Personal Relationships, Network Embeddedness, and Social Inclusion" edited by Miranda J. Lubbers (Autonomous University of Barcelona, Spain).

(C) 2021 by the authors; licensee Cogitatio (Lisbon, Portugal). This article is licensed under a Creative Commons Attribution 4.0 International License (CC BY).

\section{Introduction}

Contemporary societies are globally undergoing a significant ageing phenomenon. The ageing of societies poses challenges for families, communities, markets, and governments, but social, cultural, and economic inequalities shape its effects. In this global context, Chile represents an excellent case study. It has one of the largest ageing populations in South America (ECLAC, 2015) and is one of the most unequal countries in the OCDE (OCDE, 2018). Furthermore, the current Administration of Founding and Pensions system is the worlds' first state-endorsed privatised pension system (Lear \& Collins, 1991; Solinamo, 2017). This system has generated significant inequalities in the ageing population, especially considering their socioeconomic status.

In this specific context, we aim to discover how cumulative social inequalities intersect with social networks in facilitating or hampering social support over time, impacting retirement experience. Besides, we want to observe if and how life trajectories of older people from different socioeconomic statuses affect how people 
build their social support networks (SSNs) in terms of structure and composition. The research was carried out from a mixed-method perspective. Fieldwork was done between October 2019 and January 2020 in Santiago, Chile. Thirty life histories of retirees and their SSNs were collected, which will be the primary data used in this article.

The goal is to clarify some of those disadvantages based on the ego's socioeconomic status over time and retirement. The results show that SSNs are embedded with life histories during retirement, affecting later life. We identified three trajectory types, and for each one SSNs means something different. Firstly, it could be a net of people and institutions allowing ego to have other opportunities available, as "trajectory of opportunities." Secondly, there are "trajectories of constraints," which mean that their SSNs constrains those opportunities limited by the accumulative disadvantages over the life course. Finally, for those cases nominated as "changing trajectories," their SSN is more flexibly defined as a possible net of opportunities, but also a constraint. These could vary through different periods of life, according to personal networks of ego and historical context.

\section{Theoretical Framework}

The question of how the socioeconomic status of a person influence their retirement has been a theme in gerontology since the early days of disengagement theory (Cumming \& Henry, 1961) and in the criticisms of activity theory (Birren \& Schroots, 2001; Diggs, 2008; Martins \& Liberalesso, 2017), as the latter did not consider the finances of an older person. Some scholars from the theory of modernisation understand how changes in society's economy would impact the daily lives of older people (Aboderin, 2004; Achenbaum \& Stearns, 1978; Powell \& Hendricks, 2009; Rhoads, 1984). Kuypers and Bengtson (1973) established that vulnerability, health, and economic status are fundamental to understanding an older person's current situation. More recently, the critical gerontology theory has focused on how old age is socially constructed and determined by a political economy that pressures and constrains older people by class and age (Estes, 2008; Estes et al., 1982). Moreover, there is still some disagreement over how older people's experiences are different according to their socioeconomic status during retirement, to which this article seeks to contribute.

Older people's support during retirement could be considered a valuable resource to deal with any difficulties. A recent study in Canada (Menec et al., 2019) shows that loneliness in older people is related to their class, gender, and age. They also discovered that older people living in urban areas are more likely part of a low socioeconomic context, and therefore more susceptible to being socially isolated. If the person has a solid SSN, they are less likely to be isolated and lonely. There is evidence that family relationships are the most impor- tant ones to help with daily life and health-related issues (Cornwell et al., 2009). Also, personal networks' size increases or decreases in older age mainly because there are changes in their groups of family and friends (Bowling et al., 1995; Cornwell et al., 2009). The network size and composition impact the well-being of older people (Fung et al., 2001). For example, being retired with a spouse or a partner and have a pension increases the feeling of economic security (Litwin, 2009). Other research in the US identified that the frequency of socialisation with neighbourhood, religion, and volunteering is positively associated with the level of connectedness of the ageing population (Cornwell et al., 2008).

In general, SSNs are essential in daily life, especially when considering older people who have already accumulated some advantages and/or disadvantages throughout their lives. Besides, SSNs are not static as they change over time (Bowling et al., 1995), according to the type of social support enquiry. The social support could be material aid, intimate interaction, giving advice, physical assistance, feedback, or positive social interactions (McCarty et al., 2019). Besides, there are negative social interactions that act as anti-support, which are relevant to the analysis of SSNs (Offer \& Fischer, 2018). This article only looks at material aid, which is anyone giving ego economical help (or vice versa). Even though studies primarily concentrated on ties of material aid, there is still discussion about how other factors intersect those personal networks. Some of those are adversities without control of the ego, which could differ from reciprocity norms (Offer, 2012), stigmatisation (Offer, 2012; Ray et al., 2016), power differentials among people (Lavee, 2016), and even exclusion from family networks (Lubbers et al., 2020). These factors can lead to the inability of older people to reach each other and therefore be socially excluded. The goal is to clarify some disadvantages based on the socioeconomic status of ego over time and their retirement.

\section{Methodology}

This research collected longitudinal data of 30 older people in Santiago, Chile, aged between 60 and 98, 15 men and women from different social classes, using a mixed-methods approach (Bellotti, 2015; Domínguez \& Hollstein, 2014; Froehlich et al., 2020;). Table 1 presents a summary of participants' sociodemographic characteristics. All interviewees were retired at the time of the interview.

Data were collected from October 2019 to January 2020 in Santiago. Participants completed their life history, SSNs and timeline (Ortiz et al., 2021). Data collection followed these steps: First, each participant was asked about their complete life history, guided by the interviewer. After that we asked: If you had to decide, which were the most important events of your life (for you)? Older people usually choose 3 to 9 events. Afterwards, all participants choose the important people 
Table 1. Summary of socio-demographics of the respondents.

\begin{tabular}{llcr}
\hline & Sociodemographic information & $\%$ & Number \\
\hline Gender & Female participants & $50 \%$ & 15 \\
& Male participants & $50 \%$ & 15 \\
Age & Average of age & - & 80 \\
& Range & - & $60-98$ \\
Social class & High-class district & $33 \%$ & 10 \\
& Middle-class district & $33 \%$ & 10 \\
& Low-class district & $33 \%$ & 10 \\
\hline
\end{tabular}

on that specific event. Then, the SSN questionnaire with the name generator tool was applied. Finally, at the interview, we asked for the SSN of each participant. All the data collected is retrospective, as it is constructive from the persons' perspective. People were interviewed more than once, and after all the interviews, the main researcher assigned pseudonymous (randomly) to participants.

SSNs were based on the questionnaire "Multiple Name Generators for Social Support" (Barrera, 1980; McCarty et al., 2019). In addition, negative social interactions were measured (Leffler \& Gillespie, 1986; Offer \& Fischer, 2018), as well as material aid, intimate interaction, advice, physical assistance, feedback, and positive social interactions. Even though all dimensions of social support were measured, the analysis concentrated primarily on material aid. This decision was made considering recent discussions about the relevance of social support in dealing with changes from having a salary to a pension (Osorio, 2007). Then, it was decided to only focus on one dimension, which is closer to the socioeconomic aspect analysed here. Also, all questions were asked to ego in both directions: from ego to alters and from alters to ego.

Finally, a narrative analysis was performed (Riessman, 2009) per life history (Ortiz et al., 2021) as well as an analysis of the structure and composition of each personal network collected (Bidart et al., 2020; Crossley et al., 2015; McCarty et al., 2019; Perry et al., 2018). Vennmaker, Nvivo12, and R were used to collect and analyse the data. The primary author did the coding in Nvivo12 in three steps: First, all the interviews were coded according to the topic of the guided interview. Those were broad codes, such as school in childhood. Second, detail codes were created as hungry in childhood or presence of violence in childhood. Finally, there was the last revision of all of them to give some coherence among coding. Each step was separated from the other one by a couple of days. After all that process, we constructed each person's timeline (Ortiz, 2021) using their interviews. Finally, we revised all the coding and timelines, which allowed us to identify the three types of trajectories discussed below.

\section{Results}

\subsection{Types of Trajectory and Social Support Networks}

We identified three types of trajectories among the older people interviewed. The "trajectories of opportunities" are those cases in which ego had the opportunity to decide their life path, as they came across different chances that help them. Events were provided mainly by people in their SSNs. On the contrary, the "trajectories of constraints" are egos living by the necessity to resolve their immediate adverse circumstances (constraints) throughout their lives, which is the main factor in how their life histories are constructed. In those cases, older people do not have so many options because someone close required their help. They do not have many options, rather than working informally (for example) to pay the rent. The main difference between opportunities and constraints is the direction of the material aid: In the first one, older people tend to receive material from others, and in the second one, older people tend to give material assistance. Finally, the "changing trajectories" refers to egos that transited from a trajectory of constraints to a trajectory of opportunities, or the other way around. Among the cases collected, the change between one and another trajectory was mainly because of changes at the macro-level of society. For example, the dictatorship makes some specific people earn more money. In total, the trajectory of opportunities had seven cases, trajectory of constraints had 18, and changing trajectory had five (see Table 2). Each trajectory will be explained in the following section, as well as how SSNs are associated with life histories and retirement. The supplementary material includes a table with a more detailed description of each case and to which trajectory they were identified.

\subsubsection{Trajectory of Opportunities}

The trajectory of opportunities refers to the life histories of people who had, as the name indicates, the chance to decide their life paths. They told us how they managed to make decisions over time, although their difficulties were not so intense to stop them from making their own 
Table 2. Description of each trajectory and the percentage of respondents associated.

\begin{tabular}{|c|c|c|}
\hline Type of trajectory & Description & Percentage of responders \\
\hline $\begin{array}{l}\text { Trajectory of } \\
\text { opportunities }\end{array}$ & $\begin{array}{l}\text { Life histories of people who had the opportunity to decide their life } \\
\text { paths. Their difficulties are shadowed by their opportunities. Also, } \\
\text { their SSN are an essential part of the social net of these people. }\end{array}$ & $23.3 \%(n=7)$ \\
\hline $\begin{array}{l}\text { Trajectory of } \\
\text { constraints }\end{array}$ & $\begin{array}{l}\text { They live guided by the necessity to resolve their immediate } \\
\text { negative circumstances (constraints) throughout their lives. } \\
\text { Those problems need to somehow resolve, and thus their SSN } \\
\text { acquire a critical role, often as constraints rather than helpers. }\end{array}$ & $60.0 \%(n=18)$ \\
\hline $\begin{array}{l}\text { Changing } \\
\text { trajectories }\end{array}$ & $\begin{array}{l}\text { The changing trajectories are when a person transits from one of } \\
\text { the trajectories to the other. Ego is changing from one trajectory } \\
\text { to another by external circumstances (institutions, context, natural } \\
\text { disasters, pandemics) to his/her decision. }\end{array}$ & $16.7 \%(n=5)$ \\
\hline
\end{tabular}

choices. Like any person, they had challenges, although their opportunities were more relevant for the establishment of their path in comparison with their difficulties. Thus, SSNs are an essential part of the social network of these people.

The fact that the SSN questions asked were based on the most critical events in the lives of older people, many positive events are included in the trajectories of opportunities. For example, these cases mainly choose marriages, childbirths, jobs, scholarships or university graduations, and moving home. Only in the case of Juan there was an adverse event, which was the death of his son in an airplane accident. Accordingly, the support in these instances is associated with these events.

Seven trajectories of opportunities were identified, in which four were older women and three were older men. Regardless of their socioeconomic status, all of the interviewees were living in a high-class district.

In general, the SSNs in the trajectory of opportunities had people nominated as necessary, although not all of them were giving/receiving support to the ego. It was common to see some specific people giving or receiving only one dimension of support, like having different people with different roles. That probably promotes a tendency to have more diversity among the support they received as ego. Moreover, the partner was very central to giving and receiving many different dimensions of support, especially material aid. The groups of family, work, and friends were very clearly separated in two different parts of the network and did not know each other. Those separations create less dense networks. The family acts as the primary source of intimate interaction, advice, and feedback. They usually contracted someone external such as a domestic worker to provide physical assistance and a therapist to provide advice and intimate support; both paid by the primary source of material aid in the house.

Most of those nominated as trajectories of opportunities had some common characteristics. The pensions were the highest in the sample. The majority do not live alone except for Juan, whose daughter was trying to encourage him to move and live with them at the time of the interview. David, Alvaro, and Juan have at least one additional property (to be rented and/or for holidays), and they were all working by choice as consultants in their areas of expertise.

The existence of cumulative advantages and disadvantages in the lives of older people has been argued in the literature (Dannefer, 2003, 2018). From that point of view, the trajectory here named "of opportunities" could be related to their idea of life mainly with cumulative advantages. Accordingly, those advantages are not decided by the same individuals, which happen independently of their merit. Reportedly, the trajectory of opportunities has much in common with those, looking into the tendency to accumulate specific characteristics (opportunities) over time, which has an impact on later life.

The case of Margarita is an illustrative example of this trajectory. She was 78 years old and living in a high-class neighbourhood at the time of the interview. Figure 1 illustrates her timetable.

The first event Margarita chose was a Christmas celebration in her childhood. At this time, the support flowed mostly from others to her; for instance, her father paid for everything. Money was not a topic of conversation in her childhood or adolescence. Margarita had negative ties with her cousins and played with neighbours.

Margarita's second event was her marriage. Her network had changed considerably. Now, she mostly received support from her family, although her relationship with her mother was conflictive. She met weekly with a group of female friends to pray. They provided positive interactions rather than other kinds of support. Her husband offers the primary salary.

When her children were grown, Margarita had an opportunity to work in a school. That was a significant and exciting change for her, which her support network represents. She started to socialize more at work and did not need to receive material aid from others (like sisters and parents). Although, her husband continued to 


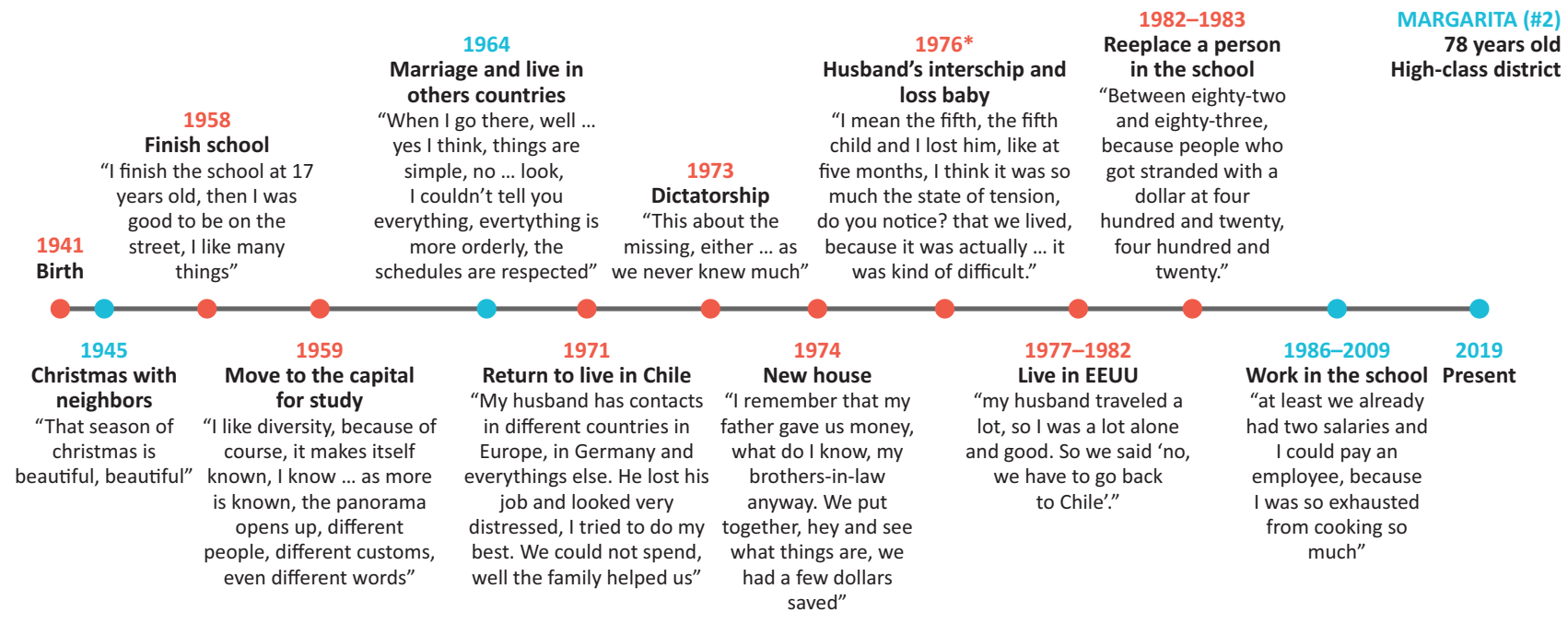

Figure 1. Margarita's timeline.

give significant economic support, feedback, and positive interactions. Her mother and a friend now support her intimately, and she lost contact with her prayer group of friends. Another positive change was having a salary for the first time. She mentioned this event as a proud moment, because she had the opportunity to help her family economically.

Her last network corresponds to the present (see Figure 2). Now, her support network is composed of friends, family, and two others. She meets again with the friends with whom she used to pray. Her therapist appears to be her most intimate support and provider of advice. She has a pension, which helps in the household. Her network shows that she receives many types of support from different people. Also, she is very active in her groups (prayer group) and values them enormously.
Margarita represents a very organized, fluid type of life. She travelled to other countries, which gave her the chance to learn from others. The economic aspect was not central in her life course.

\subsubsection{Trajectory of Constraints}

Trajectories of constraints are when people are not able to manage their life paths on their own. Instead, they live guided by the necessity to resolve their immediate adverse circumstances (constraints) throughout their lives, which is the main factor affecting how their life histories are constructed. Those immediate circumstances are problems that they need to resolve somehow, and thus their SSN acquires a critical role, often as constraints rather than helpers. This approach is particularly close to
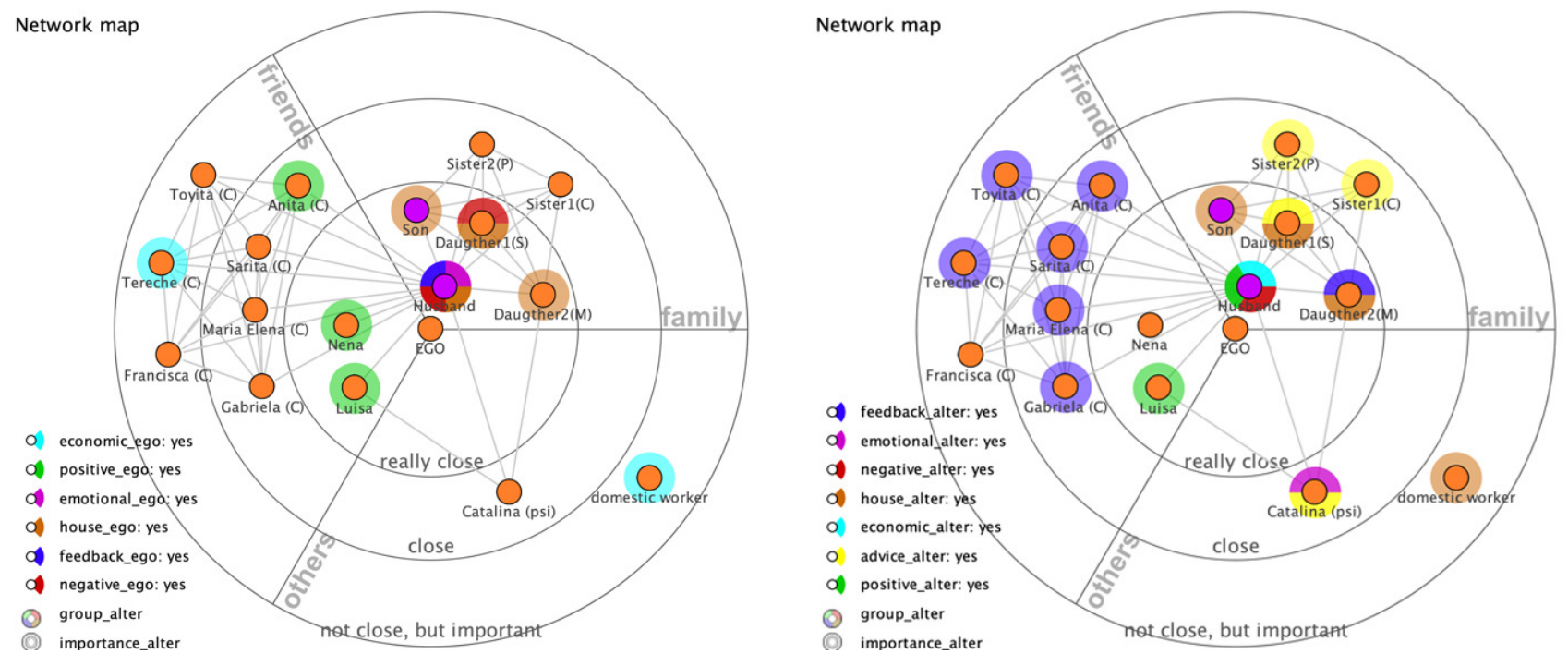

Figure 2. SSN of Margarita in 2019: The left network is the support from ego to alter, and the one at the right side is from alter to ego. Notes: We measured the material aid, intimate, advice, physical assistance, feedback, positive social interaction, and negative social interactions. Each type of support is represented with one color (in the same order): light blue, pink, yellow, brown, blue, green, and red. 
what has been proposed by González de la Rocha (2004), studying different Latin-American countries. She used the terms or accumulative disadvantages to explain that there has been an impact from excluding the labour market into other aspects of social life. She demonstrated that the lower classes usually accumulate conditions of surviving in this context, leaving them in a more vulnerable situation.

As mentioned, the types of events chosen by the people interviewed marked in some way the configurations of their SSNs. In general, the trajectories of constraints were constantly interrupted by traumatic and violent events, not only from an emotional point of view but also from a physical sense. Approximately less than half of the events nominated were positive ones, including buying/constructing homes, marriages, jobs, and childbirths. The majority were adverse and traumatic events for the interviewed: sickness and death of someone close (parents, partners, children), accidents at work, job loss, economic problems, and health problems. Moreover, some of them identified events related to the dictatorships, such as having a son detained by the military and never reappearing.

In general, there were more life histories as trajectories of constraints identified in the complete sample of participants. Specifically, there were 18, comprised of ten older women and eight older men. Regarding the socioeconomic status of ego in this trajectory, ten were living in the low-class district and eight were in the middle-class community. Trajectories of constraint among older people living in the high-class district were not found, showing an association between socioeconomic status and trajectory type. At least 14 of these cases had pensions of less than the minimum wage. In the majority of those cases (more than 12), those pensions were state subsidised, and the participants did not have savings. Also, ten are widow(er)s and eight are not.

Their support networks commonly looked more connected and had fewer structural holes in between alters.
The location where alters were living appears to be relevant. Many of the closest alters giving/receiving more support to/from ego were living in the same district, which implies needing less money to see each other. In fact, at times, it was in the same couple of blocks or land. Thus, there was a sense of community between them, as many lived in the same neighbourhood and shared the same histories. The family and close friends were the ones giving/receiving material aid, intimate interaction, advice, and feedback. The family composition suffered more changes over time in comparison with the other trajectories. Those interactions were also with people who were not so close, in contrast with the trajectories of opportunities. Moreover, we found less domestic worker presence for this type of trajectory. The groups of friends varied and changed over time, depending mainly on the type of activity that united them, such as a sport, club, or political affiliation.

In the trajectory of opportunities, an association with the idea of cumulative advantages is claimed. In the case of the trajectory of constraints, it would be the contrary, as it is associated with the concept of cumulative disadvantages proposed by Dannefer $(2003,2018)$. Again, we refer to a systematic tendency to accumulate certain adverse circumstances (constraints), such as those already recognised as part of the trajectories of constraints. In the following sections, some examples of cases categorised as trajectories of constraints are presented with their SSN over time, in which shows associations between the two can be seen.

An example of this trajectory is the case of Catalina (see Figure 3). At the time of the interview, she was living in a low-class neighbourhood and was 78 years old.

In comparison with Margarita, Catalina's tragic life events started very early, with many events in her childhood. Her first event was a very traumatic one, which shaped her whole life. When she was 20 years old, she started to work (for the second time) in another home as a domestic worker. In that work, she was drugged and raped by her boss's son. From that event, she got

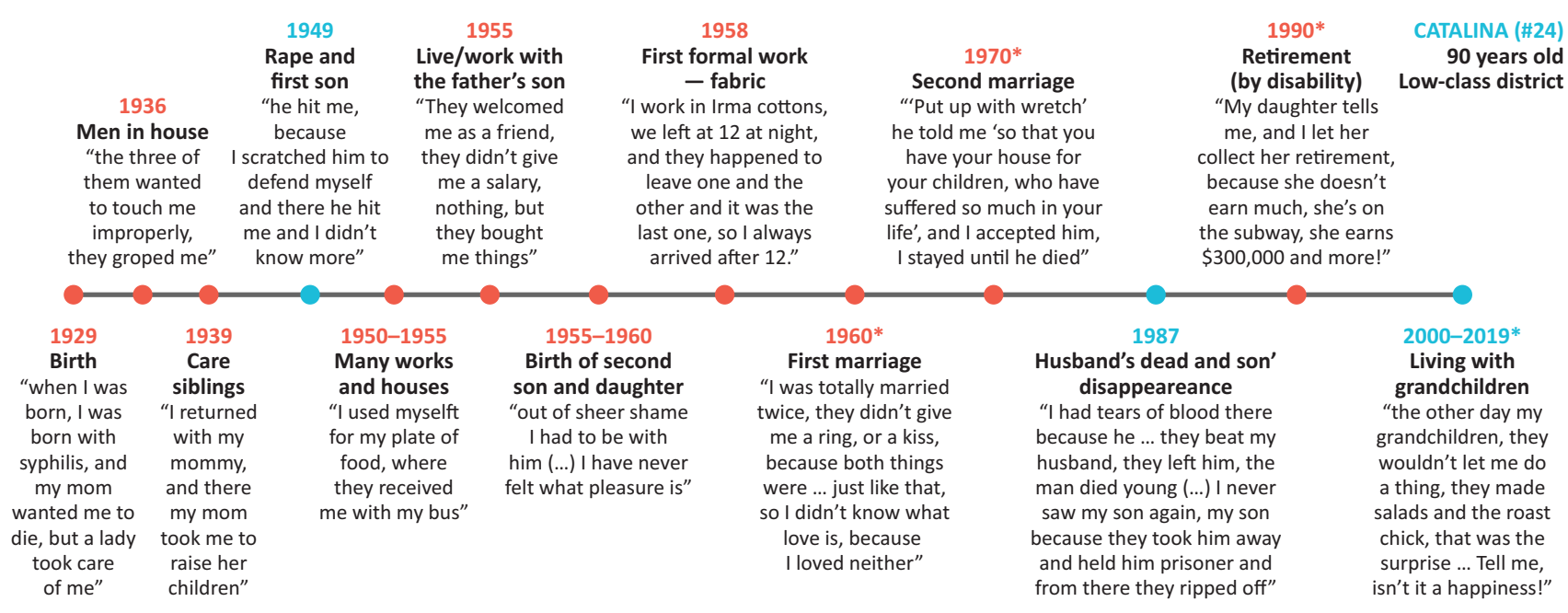

Figure 3. Catalina's timeline. 
pregnant and had her first son. She had no support at all. Her mother was an alcoholic. She was the financial support of her siblings, and she had to work since she was ten years old. The only person who helped her in this situation, specifically during the pregnancy, was her doctor.

After having her first child, she returned to work almost immediately. For nearly ten years, she had many informal jobs, all as a domestic servant. It was difficult for her in these jobs for more than a year because the employers didn't let her be with her son. As a result, she never had someone to help her take care of him, and she had to generate enough income to support her son, herself, and her younger siblings. In addition, her mother spent many nights out due to drug problems, which made Catalina the most critical economic support for her siblings. That improved a bit when her son was able to start school, and her siblings were old enough to take care of themselves. She describes those years as very tough in economic terms; she didn't sleep much and never thought of having holidays, but still, she remembers it proudly.

The death of people close to her has shaped her whole life, something prevalent between older people living in the same district. She continues working as a domestic worker. She has more support from her family; however, she still needs to pay for the house, health, bills, and other necessities. Catalina was always the constant economic support of her family, among other kinds of supports. Her second event was when her son was missed (because of the dictatorship), which also happened to her husband. She had to keep going with the rest of her family, depending on her salary as a domestic worker. In the SSN of this event, she described her husband and son as the main worries of that year. She found out later that her husband died. Her son got the opportunity to go to another country. However, she lost contact with him. Currently, she knows that he died a couple of years ago.

The last event is her present (see Figure 4). She divided her groups into family and friends. Her essential support is her daughter and son. Also, she mentioned some grandchildren with whom she currently lives. She received a basic pension to pay for some food and two bills in the house. They do not need to pay rent because it was already entirely bought by her. She is also attending a communitarian centre at least two days a week - a place where she finds a constant group of friends as feedback and positive interactions.

\subsubsection{Changing Trajectories}

The changing trajectories are when a person transits from one of the trajectories to the other. For example, someone who started with a trajectory of constraints experiences an event (e.g., change of country, a job opportunity or a child increasing their salary) that changes their trajectory to one of the opportunities. The same could happen the other way around: Someone who has a trajectory of opportunity, but one event (e.g., job loss or health problem) changes the trajectory to constraints. In that sense, ego changes from one trajectory to another by external circumstances (institutions, context, natural disasters, pandemics) to their decision.

Those people identified as changing trajectories constructed their SSNs by their most important events. In this case, some were positive events, such as marriage, childbirth, and graduation, and only one event was adverse, which was the parents' death in two cases.

There were five changing trajectories (three upward and two downward), of which four were older men and one was an older woman. Regardless of their socioeconomic status, three were from a high-class district and
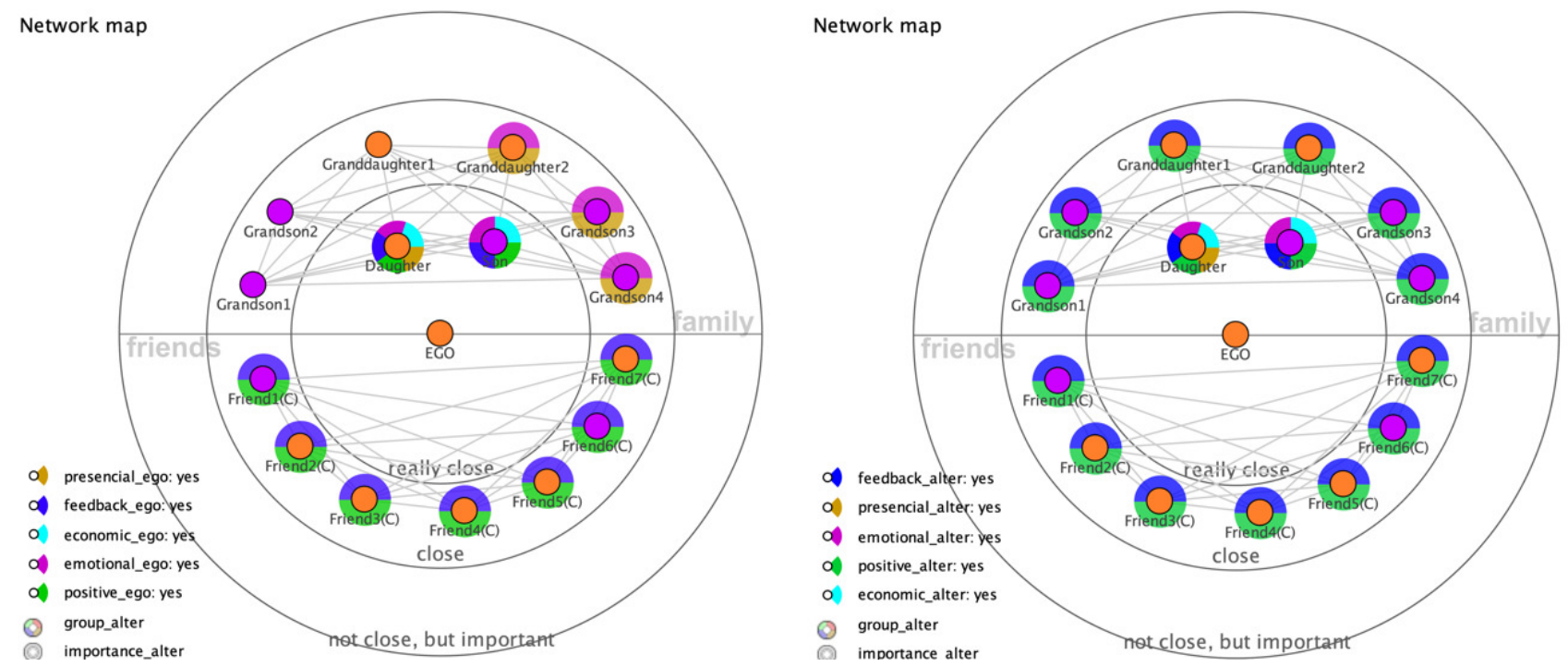

Figure 4. Catalina's SSN in 2019. The left network is the support from ego to alter, and the one at the right side is from alter to ego. 
two from a middle-class one. There were no people from the low-class district identified with this trajectory type.

In general, the changing trajectories were associated with SSNs. As with the trajectory of opportunities, the family composition did not change a lot over time and was defined by kin. From these five cases, the four men had been giving material aid to many people over time, especially family members. At the core of the network were those kin-related people with whom they had shared more experiences throughout life, appearing in many different stages. The groups in which they had been part were varied, and there were changes between those events. In this trajectory, it was difficult to identify a tendency about the density and variety of dimensions of supports, as it was diverse. Finally, closeness (spatial and geographical) appears to be relevant to the everyday interactions of those cases.

These cases were participants who were not living alone and were from the middle and high-class districts. Felipe, Pedro, and José had pensions that were greater than the minimum salary. Felipe had two additional properties being rented and was working by choice as a consultant for the Chilean Investigations Police (PDI), the police institution for which he had worked his whole life. Felipe had the highest pension of all the participants. However, he did not finish school because of monetary reasons and had worked as a taxi driver and repairing cars, among other jobs. He had been living a life of constraints, but when the dictatorship started and he joined the PDI, his earnings started to rise, especially at the end of his career. Felipe's history shows us how the macroeconomic level changes. The dictatorship profoundly impacted his life and made his trajectory move to one of the opportunities (see Figure 6). Pedro was a similar case, although he had the opportunity to study engineering, which was the factor that spurred his career. Moreover, since the dictatorship in Chile, engineers have become one of the best-paid careers. Thus, Pedro also moved from a trajectory of constraints to one of the opportunities.
These three trajectory types were identified by the life histories of the older people interviewed, meaning that all are from their perceptions of their own lives. The changing trajectory is the only one that does not have an equivalent in Dannefer's cumulative inequality theory (Dannefer, 2018; Ferraro et al., 2009). The perception of each person to construct their ideas of disadvantages and advantages is also considered, even though nothing has been mentioned that is similar to the changing trajectory in that theory, at least from these authors. That has been framed as a cohort effect. This study was more focused on how the person tells their stories and their relational aspects over time.

In this case, the example is the timeline of Felipe (see Figure 5). He is 78 years old and was living in a high-class district at the time of the interview.

He was born in Maipu, his father was a taxi driver, and his mother used to take care of the house. When he was 18 years old, he finished school, worked a couple of years as a taxi driver, worked in a factory, and later started working on the PDI. One year after that, his daughter was born. He did not earn a significant amount of money in the PDI, so he starts working in a factory, where his salary was double. However, he began to miss the institution (PDI) and came back to work there until his retirement. After his retirement, he continued working in his own properties' agency until today.

Felipe mentioned many events, and all happened after he was 18 years old. However, he identified two events as the most important ones: his marriage and when his mother died. In the first event, he had economic support from his father. He and his wife live in his parents' house to reduce costs and have some savings for the first year. He recognized that his father was essential in terms of the money in that period because it was significantly challenging the first years on the PDI institution, as the salary was meagre.

The second event chosen by Felipe was in 2002. His mother had a stroke, and later the same year, died. That was a difficult moment for him, and he talks about it in

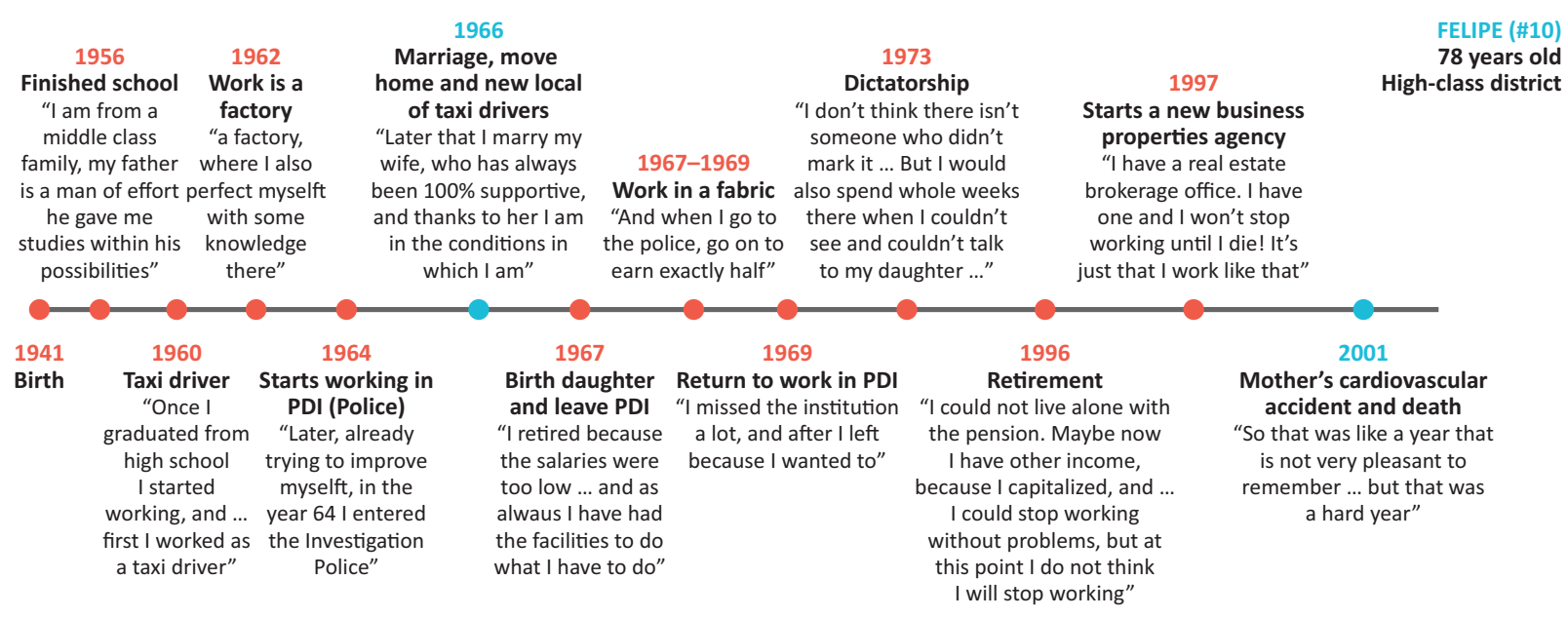

Figure 5. Felipe's timetable. 
a very emotional way. Even though he lost many people from the institution (PDI), during the dictatorship, losing his mother was the most significant one. In that year (and today), he was in an ideal economic situation: He has a considerable amount of money from his pension and complements his earnings from his properties agency and two rented apartments. He had the opportunity to go on holidays to other countries of South America with the entire family. Also, he highlights that in that period (and currently), he used to financially help his daughter, wife, and two grandkids. He also mentioned that he could pay for services to take care for his mother and father, and this was possible due to his efforts to save and produce money. This support is shown in Figure 6. Felipe's case represents a life transformed from living in a low-class neighbourhood to living in a high-class area. This was possible due (as he argues) to his efforts. He was also able to overcome some struggles thanks to the support of his father and wife.

\subsection{Differences by Socioeconomic Status}

The retirement experience is shaped by the events that happen in the lives of older people. The main difference among the cases is between people who had the opportunity to decide their life paths and those constrained by the necessity to resolve their immediate circumstances throughout their lives, which ended up constructing their paths. In this particular study, the results suggest that the first path was associated with older people currently living in the high-class districts of Santiago (see Table 3). Meanwhile, it coincided that older people living in middle and low-class districts were closer to the second way of life. Of those in the changing trajectories, three were from the high-class district, and two were from the middle-class district.

Accordingly, some literature (Berkman \& Glass, 2000; Cohen et al., 2000; Guiaux et al., 2007; Perry \& Pescosolido, 2012, 2015; Taylor, 2011) described the SSN as a safety net, which helps whenever needed to cope with difficulties. Some alters of that network could have a solution to a problem, or considering the economic aspect, could be the ones with the money necessary to help. Also, some alters could help find a job or another opportunity to lead to a better socioeconomic situation for ego. In that sense, the SSN could allow for expanded opportunities available to ego. Although, from another point of view and as it has been presented here, the SSNsof ego could be a consequence of the accumulative disadvantages throughout life.

This section has presented how socioeconomic status shapes one's retirement. Some events were
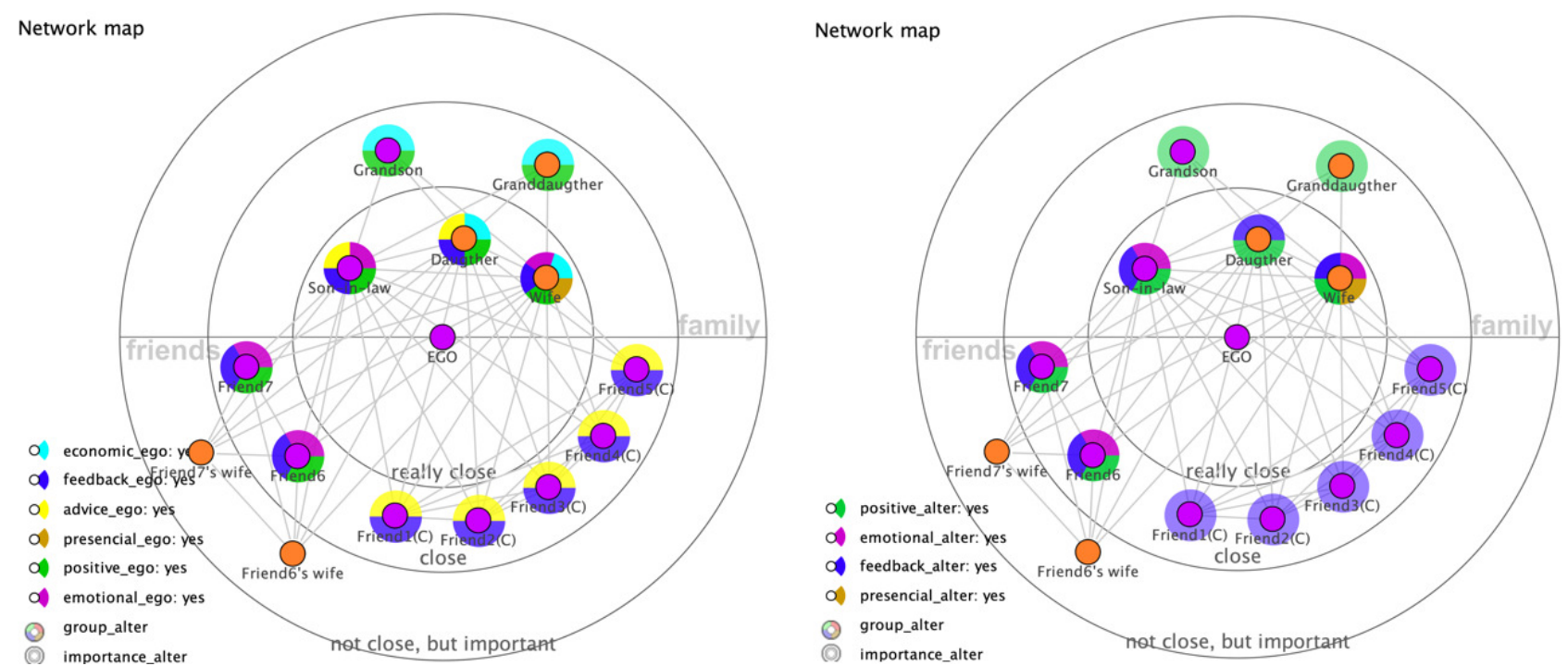

Figure 6. Felipe's SSN in 2019: The left network is the support from ego to alter, and the one at the right side is from alter to ego.

Table 3. Total number of participants by trajectory type and socioeconomic status.

\begin{tabular}{llccrr}
\hline & & \multicolumn{3}{c}{ Socioeconomic Status of Ego } \\
\cline { 3 - 6 } & & High-class District & Middle-class District & Low-class District & Total \\
\hline Trajectory & Opportunities & 7 & 0 & 0 & 7 \\
& Changing & 3 & 2 & 0 & 5 \\
& Constraints & 0 & 8 & 10 & 18 \\
\hline
\end{tabular}

Note: $p<0.001$ with Fisher's Exact Test with simulated $p$-value (based on 10,000 replicates). 
experienced differently according to the person's socioeconomic status-for example, their first job experience. In the case of Margarita, she had the opportunity to choose whether to work later in her life. Conversely, Catalina had to renounce school to start working at ten years old to support herself and her family economically. Similarly, Luis needed a job to support his family, so he ended school earlier and started working when he was 13.

There are other aspects in these lives that illustrate the variances among these cases. For those living in lowclass districts, it was common to have informal jobs during their life trajectories, as observed with Catalina and Luis. Another aspect was the role of childcare. On the one hand, taking care of children could be considered an option if there was enough money to contract a domestic worker. On the other hand, it could be seen as a non-option and more a necessity, implying the need to ask for support to take care of children. An additional difference was whether people had holidays and where they would go. The older people living in the low-class district had more traumatic events in their lives, which could be a measure of accumulated inequality.

\section{Conclusions}

Retirement is the termination of work, which implies moving from a salary to a pension. As it is argued that the pension system in Chile does not work, the focus was on how other sources of economic support may or may not help retired people. During retirement, the SSN of someone could be a net of people and institutions, allowing ego to have other opportunities available or constraints to opportunities limited by accumulative disadvantages throughout life. According to the personal network of ego and historical context, that could vary throughout different periods of life. As they are explored, all lives are found to be completely different. They have other actors, ties, forms of interactions, emotions, and experiences. Therefore, their SSNs are shaped by their life histories in different ways as well. The complexity of the topic sometimes makes it difficult to study properly. However, looking through people's life histories and their networks over time seems to be a helpful way to approach it, as has been already done by other researchers (Bidart, et al., 2020; Crossley et al., 2015).

Our main finding is that the trajectory type will impact a person's SSN and thus the experience of retirement. People identify events and discuss the characteristics of their networks at the time. Some SSNs are helpful, while some are exploitative. The support and exploitations seem to accumulate over time, resulting in paths spiralling up or down in economic selfsufficiency. Moreover, the trajectories are shaped by the socioeconomic status of ego, which eventually affects their retirement.

This research has established that SSNs during retirement are shaped by the ego's socioeconomic status and life history. The actual life history depends on the type of trajectory they have experienced: opportunities, constraints, or change. Therefore, the situation of older people can be fully understood considering their life course, including actors, relationships, emotions, narratives, and experiences the latter entails. Despite all that has been said, this research had the limitation of representativity, as it is a study case. Future research should look at this issue in longitudinal surveys with representative data.

\section{Acknowledgments}

Becas Chile funded this study from the Chilean Agency of Research and Development ANID [2018-72190281]. We thank the reviewers for their time reading our manuscript and their comments on improving the article. Also, thanks to Miranda Lubbers for coordinating this thematic issue of which this article is part.

\section{Conflict of Interests}

The authors declare no conflict of interests.

\section{Supplementary Material}

Supplementary material for this article is available online in the format provided by the author (unedited).

\section{References}

Aboderin, I. (2004). Modernisation and ageing theory revisited: Current explanations of the recent developing world and historical Western shifts in material family support for older people. Ageing \& Society, 24, 29-50.

Achenbaum, W. A., \& Stearns, P. N. (1978). Essay: Old age and modernization. The Gerontologist, 18(3), 307-312.

Barrera, M. (1980). A method for the assessment of social support networks in community survey research. Connections, 3, 8-13.

Berkman, L. F., \& Glass, T. (2000). Social integration, social networks, social support, and health. In L. F. Berkman \& I. Kawachi (Eds.), Social Epidemiology (pp. 137-173). Oxford University Press.

Bidart, C., Degenne, A., \& Grossetti, M. (2020). Living in networks. Cambridge University Press.

Birren, J. E., \& Schroots, J. J. F. (2001). The history of geropsychology. In J. E. Birren \& K. W. Schaie (Eds.), Handbook of the psychology of aging (pp. 3-28). Academic Press.

Bowling, A., Grundy, E., \& Farquhar, M. (1995). Changes in network composition among the very old living in inner London. Journal of Cross-Cultural Gerontology, 10, 331-347.

Cohen, S., Underwood, L. G., \& Gottlieb, B. H. (Eds.). (2000). Social support measurement and intervention. A guide for health and social scientists. Oxford 
University Press.

Cornwell, B., Laumann, E., \& Shumm, P. (2008). The social connectedness of older adults: A national profile. American Sociological Review, 73(2), 185-203.

Cornwell, B., Schumm, P., Laumann, E. O., \& Graber, J. (2009). Social networks in the NSHAP study: Rationale, measurement, and preliminary findings. Journal of Gerontology: Social Sciences, 64B(S1), i47-i55.

Crossley, N., Bellotti, E., Edwards, G., Everett, M., Koskinen, J., \& Tranmer, M. (2015). Social network analysis for ego-nets. SAGE.

Cumming, E., \& Henry, W. (1961). Growing old: The process of disengagement. Basic Books.

Dannefer, D. (2003). Cumulative advantage/disadvantage and the life course: Cross-fertilizing age and social science theory. Journal of Gerontology, 58B(6), 327-337.

Dannefer, D. (2018). Systemic and reflexive: Foundations of cumulative dis/advantage and life-course processes. The Journals of Gerontology, 75B(6), 1249-1263.

Diggs, J. (2008). Activity theory of aging. In S. J. Loue \& M. Sajatovic (Eds.), Encyclopedia of aging and public health (pp. 79-81). Springer.

Domínguez, S., \& Hollstein, B. (2014). Mixed methods social networks research. Cambridge University Press.

ECLAC. (2015). Anuario estadistico de América Latina y el Caribe [Statistical annual report of Latin America and the Caribbean]. CEPAL.

Estes, C. (2008). Social security privatization: An ideologically structured movement. Journal of Sociology and Social Welfare, 35(1), 75-104.

Estes, C., Swan, J., \& Gerard, L. (1982). Dominant and competing paradigms in gerontology: Towards a political economy of ageing. Ageing and Society, 2(2), 151-164.

Ferraro, K., Shippee, T., \& Schafer, M. (2009). Cumulative inequality theory for research on aging and the life course. In V. L. Bengston, D. Gans, N. M. Pulney, \& M. Silverstein (Eds.), Handbook of theories of aging (pp. 413-434). Springer.

Froehlich, D., Rehm, M., \& Rienties, B. (2020). Mixed method social network analysis. Routledge.

Fung, H. H., Carstensen, L. L., \& Lang, F. R. (2001). Agerelated patterns in social networks among European Americans and African Americans: Implications for socioemotional selectivity across the life span. International Journal of Aging \& Human Development, 52, 185-206.

González de la Rocha, M. (2004). De los "recursos de la pobreza" a la "pobreza de recursos" y a las "desventajas acumuladas" [From the "resources of poverty" to the "poverty of resources" and into "cumulative advantages"]. Latin American Research Review, 39(1), 192-195.

Guiaux, M., van Tilburg, T., \& van Groenou, M. B. (2007). Changes in contact and support exchange in personal networks after widowhood. Personal Relationships, 14, 457-473.

Kuypers, J. A., \& Bengtson, V. L. (1973). Social breakdown and competence. Human Development, 16(3), 181-201.

Lavee, E. (2016). Exchanging sex for material resources: Reinforcement of gender and oppressive survival strategy. Women's Studies International Forum, 56, 83-91.

Lear, J., \& Collins, J. (1991). Pinochet's giveaway. Chile's privatization experience. The Multinational Monitor, 12(5). https://www.multinationalmonitor.org/ hyper/issues/1991/05/collins.html

Leffler, K., \& Gillespie, D. (1986). Contact, support, and friction: Three faces of networks in community life. Sociological Perspectives, 29(3), 337-355.

Litwin, H. (2009). Social networks and well-being: A comparison of older people in Mediterranean and non-Mediterranean countries. The Journals of Gerontology, 65B(5), 599-608. https://doi.org/10.1093/ geronb/gbp104

Lubbers, M. J., Valenzuela-García, H., Castaño, P. E., Molina, J. L., Casellas, A., \& Rebollo, J. G. (2020). Relationships stretched thin: Social support mobilisation in poverty. The Annals of the American Academy of Political and Social Science, 689(1), 65-88.

Martins, J., \& Liberalesso, A. (2017). Trajectories of social participation in old age: A systematic literature review. Brazilian Journal of Geriatrics and Gerontology, 20(2), 259-272.

McCarty, C., Lubbers, M., Vacca, R., \& Molina, J. L. (2019). Conducting personal network research. Guilford Press.

Menec, V. H., Newall, N. E., Mackenzie, C. S., Shooshtari, S., \& Nowicki, S. (2019). Examining individual and geographic factors associated with social isolation and loneliness using Canadian Longitudinal Study on Aging (CLSA) data. PLOS ONE, 14(2), e0211143. https://doi.org/10.1371/journal.pone.0211143

OCDE. (2018). Inequality and income. http://www.oecd. org/social/inequality.htm

Offer, S. (2012). The burden of reciprocity: Processes of exclusion and withdrawal from personal networks among low-income families. Current Sociology, 60(6), 788-805.

Offer, S., \& Fischer, C. (2018). Difficult people: Who is perceived to be demanding in personal networks and why are they there? American Sociological Review, 83(1), 1-32.

Ortiz, F. (2021). Como usar QCA y SNA desde los métodos mixtos: Una ilustración usando las redes de soporte en jubilados [How to use QCA and SNA from mixedmethods: An illustration of using social support networks during retirement]. REDES, 32(2), 201-212.

Ortiz, F., Moyano, C., \& Moyano, D. (2021). "Por más que yo trabaje, trato de acomodar todo a mi hijo": Usos de la visualización de líneas de tiempo para comprender desigualdades de género en la academia 
["No matter how hard I work, I leave everything ready for my son": Using visualization of timelines to understand gender inequalities in academia]. CUHSO. Advance online publication. https://scielo.conicyt.cl/ scielo.php?pid=S2452-610X2021005000203\& script=sci_arttext

Osorio, P. (2007). Construcción social de la vejez y expectativas ante la jubilación en mujeres Chilenas [Social construction in old age and expectations of retirement among Chilean women]. Universum, 22(2), 194-212.

Perry, B. L., \& Pescosolido, B. A. (2012). Social network dynamics and biographical disruption: The case of "first-timers" with mental illness. American Journal of Sociology, 118(1), 134-175.

Perry, B. L., \& Pescosolido, B. A. (2015). Social network activation: The role of health discussion partners in recovery from mental illness. Social Science \& Medicine, 125, 116-128.

Perry, B., Pescosolido, B., \& Borgatti, S. (2018). Egocentric network analysis. Cambridge University Press.

Powell, J., \& Hendricks, J. (2009). The sociological construction of ageing: Lessons for theorising. International Journal of Sociology and Social Policy, 29(1/2), 84-94.

Ray, B., Grommon, E., \& Rydberg, J. (2016). Anticipated stigma and defensive individualism during post-incarceration job searching. Sociological Inquiry, 86(3), 348-371.

Rhoads, E. (1984). Reevaluation of the ageing and modernization theory: The Samoan evidence. The Gerontologist, 24(3), 243-250.

Riessman, C. (2009). Narrative methods for the human sciences. SAGE.

Solinamo, A. (2017). Pensiones a la chilena [Chilean pensions]. Catalonia.

Taylor, S. E. (2011). Social support: A review. In M. S. Friedman (Ed.), The handbook of health psychology (pp. 189-214). Oxford University Press.

\section{About the Authors}

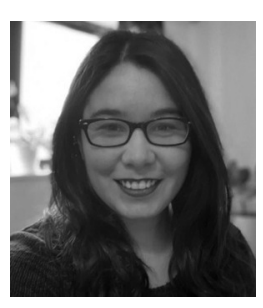

Francisca Ortiz is currently doing her PhD in The Mitchell Centre for Social Network Analysis, at the University of Manchester. She is also co-chair of the PhD and early career of Manchester Institute for Collaborative Research on Ageing (MICRA), part of the council of Women in Network Science (WiNS). Her topics of interest are mixed methods (MM and MMSNA), personal networks, relational sociology, and social gerontology.

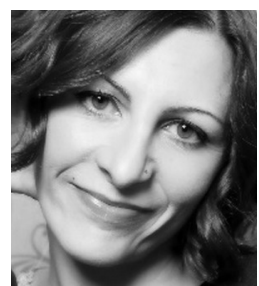

Elisa Bellotti is senior lecturer in sociology and member of The Mitchell Centre for Social Network Analysis, University of Manchester. She has published on applications of social network analysis and mixed methods in sociological fields, like criminal networks, scientific networks, and personal networks. Her recent work focuses on gender aspects of social network formations and outcomes and health networks. She has written the book Qualitative Networks. Mixed Methods in Sociological Research (2015) and co-authored Social Network Analysis for Egonets (2015). 